\title{
PRESENTEEISM IN FINLAND: DETERMINANTS BY GENDER AND THE SECTOR OF ECONOMY
}

\author{
$\overline{\text { Petri Böckerman, Labour Institute for Economic Research and University of }}$ \\ Tampere.petri.bockerman@1abour.fi \\ Erkki Laukkanen, The Central Organisation of Finnish Trade Unions, \\ erkki.laukkanen@sak.fi
}

\begin{abstract}
We study the prevalence of sickness presenteeism, using survey data covering 725 Finnish union members in 2008. Controlling for worker characteristics, we find that sickness presenteeism is sensitive to working-time arrangements. Permanent full-time work, mismatch between desired and actual working hours, shift or period work and overlong working weeks generally increase the prevalence of sickness presenteeism. The estimates by gender suggest that participation in permanent full-time work has an effect on presenteeism only for women. Furthermore, the adoption of three days' paid sickness absence without a sickness certificate and the easing of efficiency demands decrease sickness presenteeism especially in private services.
\end{abstract}

Keywords: presenteeism, working-time arrangements

\section{INTRODUCTION}

Sickness absenteeism and presenteeism are counterparts. In the case of absenteeism workers are absent from work because of sickness. In the case of presenteeism workers are present at work in spite of their sickness. Sickness absenteeism has been a focus of the EU Labour Force Surveys since the early 1970s. Sickness presenteeism is a newcomer. This concept emerged in the empirical literature as late as the 1990s. 
Decrease in sickness absenteeism reduces firms' costs, but it also contains a possibility for decreasing productivity through sickness presenteeism (Goetzel et al., 2004). Sickness presenteeism may contribute to workers' ill health and firms' costs in the long run (Dew et al., 2005; Kivimäki et al., 2005; Ahola et al., 2008), and even to dysfunctional "competitive presenteeism", which is an extreme example of competitive culture at workplaces (Simpson, 1998).

Both absenteeism and presenteeism include the possibility of productivity losses. In absenteeism direct costs are obvious, since the workers' contribution during sickness absence is non-existent. Direct and indirect costs caused by presenteeism are much more difficult to estimate (Middaugh, 2006). Notions in the literature are more or less partial and conditional upon the work culture and workers' behaviour, as well as upon the differences in data sets and estimation methods. Based on 113 studies surveyed by Shultz and Edington (2007), the costs caused by sickness presenteeism may exceed the costs of ordinary medical care, at least in the case of allergies and arthritis.

Before the evaluation of costs, knowledge of the determinants of sickness presenteeism is essential. It is reasonable to assume that sickness presenteeism is affected by the same factors as sickness absenteeism, i.e. factors related to workers and working conditions (e.g. Böckerman and Ilmakunnas, 2008). According to the literature, special attention should be paid to working-time arrangements (Webster, 2007), workers' replacement practices (Aronsson et al., 2000), attendance-pressure factors (Aronsson and Gustafsson, 2005) and personal attitudes (Hansen and Andersen, 2008).

In this paper, we examine the prevalence of sickness presenteeism by using survey data of Finnish union members from 2008. In particular, we study sickness presenteeism by gender and the sector of economy, with special focus on working-time arrangements. The Finnish case has a broader interest, because flexible working-time arrangements have increased rapidly during the 2000s. At the same time, the variation in working-time arrangements has increased substantially at workplaces. Both of these developments may have implications for presenteeism.

\section{DATA}

Our data set consists of 725 members in SAK-affiliated unions. SAK, the Central Organisation of Finnish Trade Unions, is the largest workers' confederation in Finland, and includes 26 unions. The members of these unions cover all sectors of the Finnish economy. However, most of them are blue-collar workers. It is important to note that the survey provides a broad picture of the labour market in Finland, because the union density is roughly 70 per cent (Böckerman and Uusitalo, 2006). The initial sample for the survey constitutes a random sample of the SAK-affiliated union members. 1044 individuals were selected for a 
telephone interview that was conducted by Statistics Finland in February 2008. Out of this sample, 725 persons or roughly 70 per cent participated in the interviews. The exact definitions of the variables and descriptive statistics are provided in the Appendix (Table A1).

Dependent variable of the models estimated is constructed as in Aronsson and Gustafsson (2005). Those who have never been or once been present while sick during the last 12 months are marked as zero, those who have been present several times as one, i.e. once present while sick is not enough to constitute a problematic sickness behaviour, at least twice is needed. This gives a prevalence of 30 per cent for presenteeism among the survey respondents. For women the average is higher than for men.

Explanatory variables include the sector of the economy, educational attainment, age groups, presence of children, establishment size and workers' replaceability. Replaceability includes two possibilities: replacement by substitutes and replacement by colleagues. In the literature, as discussed by Hansen and Andersen (2008), workers' replaceability and working-time arrangements have achieved the status of key explanatory variables, i.e. variables characterising the state-of-art in the organisation of work.

Besides these, the models include several dummy variables for working-time arrangements: working hours match (between desired and actual weekly working hours), shift or period work, regular overtime, and overlong weekly working hours, i.e. more than 48 hours a week, which is the maximum according to the EU Working Time Directive from 1993. The working-time match between the desired and the actual working hours is used as an indicator of working-time balance.

There are two variables that capture the rules at the workplace: the three days' rule (three days' paid sickness absence without a sickness certificate), and the efficiency rule (a statement that in tough situations efficiency substitutes for everything else). The efficiency rule is an instrument for the relative power of workers compared with employers in a competitive market situation, where tight delivery schedules, set by the employer, can undermine occupational safety and health of the workers. If the respondents agreed with the statement, as 48 per cent did, the variable for the efficiency rule was set as one, otherwise as zero.

\section{RESULTS}

The baseline estimates for presenteeism as compared to absenteeism are discussed in Böckerman and Laukkanen (2009). By pooling all the observations together, we imposed the restriction that the determination process of sickness presenteeism is exactly the same between men and women and in different sectors of the economy. In this paper, we focus on the prevalence of 
presenteeism by gender and the sector of economy, assuming that sickness behaviour may be affected by gender- and sector-specific factors. In Finland, many occupations are segregated by gender, and atypical forms of work, such as part-time and fixed-term contracts, are widely used in occupations typical for women. Moreover, the organisation of work is segregated by sector, i.e. 'taylorist' way of doing is typical for processing industries, 'flexibility' for private services and 'co-operation' for public services.

The results in Table 1 show that the model works better for women, as measured by pseudo $R^{2}$ and the statistical significance of the estimates, i.e. there are three statistically significant coefficients for men and five for women. Interestingly, if replacement (in the case of sickness) takes place in the form of substitutes, the prevalence of women's sickness presenteeism decreases by 18 per cent. ${ }^{1}$ However, for men this result does not hold, i.e. it is not statistically significant. One possible explanation is that men are not as able or willing to leave their tasks to others.

For women, permanent full-time work increases sickness presenteeism by 19 per cent, compared with fixed-term and part-time work. It is possible that women are more vulnerable to atypical work. Thus, they may be forced to show their employer their commitment more than men. Furthermore, the match between the desired and the actual hours has a stronger influence on sickness presenteeism for women than it has for men. For women the match decreases the prevalence of sickness presenteeism by 11 per cent. For men the point estimate is 7 per cent, but it is not statistically significant at the conventional levels.

Regular overtime increases men's sickness presenteeism by 13 per cent. In contrast, for women regular overtime is statistically insignificant. In addition, the presence of the three days' rule decreases men's sickness presenteeism by 9 per cent. For women the point estimate is roughly the same, but far from statistically significant. Women's sickness presenteeism is 16 per cent higher at the workplaces in which efficiency rules out everything else.

Table 2 reports the results by the sector of economy. The best fit is achieved in the private service sector, the worst in the processing industries. There are also some interesting differences in the estimates. In the processing industries the relevant policy variables are replaceability by substitutes, the working hours match and regular overtime. The possibility of replacement by substitutes decreases sickness presenteeism by 13 per cent and the working hours match

\footnotetext{
${ }^{1}$ For reasons of convenience we report that 'factor $\mathrm{x}$ increases/decreases presenteeism by y per cent'. Actually, it is the estimated marginal probability of presenteeism that increases/decreases by $y$ per cent as factor $\mathrm{x}$ is involved.
} 
12 per cent. However, in the processing industries the most important factor is regular overtime. It increases the prevalence of sickness presenteeism by 24 per cent.

In private services the relevant policy variables are permanent full-time work, shift or period work, the three days' rule and the efficiency rule. Participation in permanent full-time work increases sickness presenteeism by 14 per cent, shift or period work by 16 per cent and the efficiency rule by 14 per cent. Besides these effects, the three days' rule decreases sickness presenteeism by 16 per cent.

In the public sector, only two policy variables are relevant. This is interesting, since the public sector is clearly overrepresented in sickness presenteeism, i.e. for public sector the prevalence is $7-10$ percentage points more than for processing industries and private services. And what it comes to overlong working weeks, their impact on presenteeism is even suspiciously high: extending weekly working time over 48 hours increases the prevalence of sickness presenteeism by 57 per cent. Furthermore, permanent full-time work increases sickness presenteeism by 17 per cent.

\section{CONCLUSIONS AND DISCUSSION}

Our estimates point out that sickness presenteeism is sensitive to working-time arrangements, when worker characteristics are controlled for. In general, participation in permanent full-time work, regular overtime and overlong working weeks increase the prevalence of sickness presenteeism. In contrast, the match between the desired and the actual working hours decreases it, as discussed in Böckerman and Laukkanen (2009).

The results by gender suggest that participation in permanent full-time work has an effect on presenteeism only for women. Why is it so? One possible explanation for the fact that participation in permanent full-time work increases sickness presenteeism of women is related to the degree of control, as outlined by Aronsson and Gustafsson (2005). Women in permanent full-time work have a higher degree of control over their work, compared with women in fixed-term and part-time work. Hence, the pressure for women to work while sick is higher than the correspondent pressure for men.

The work rules have a bearing on presenteeism. If workers are eligible for three days' paid sickness absence without a sickness certificate, they work less often while sick. The pattern is especially strong for men and for those who work in private services. The results suggest adopting the three days' rule also in private sector, where every second worker is obliged to present a sickness certificate from a doctor from all sickness absences. Our comprehension is that this "zero days' rule" is not only too tough, as compared to workers in public 
sector, but is also difficult to apply, since appointment for a doctor use to take more than one day.

We also find that the presence of the efficiency rule increases sickness presenteeism in general, and especially for women and for those who work in the private service sector. Thus, efficiency rules like this are relevant in the context of presenteeism, although we have not found any other researches, where this kind of rules, measuring the business behaviour so typical to competitive markets, had been included. Besides, our results could be seen as a criticism for 'flexicurity', launched by the EU in December 2007, suggesting that the balance between flexibility (for employers) and security (for employees) is independent of the state of markets and competing interests of employers and employees.

To summarize the picture, both gender and the sector of the economy matter, i.e. the differences in gender-related attitudes and sector-related work organisation have an influence on presenteeism. Sickness behaviour of women differs from that of men. Corresponding differences also exist between the sectors of economy. Further research is needed to specify the reasons for these differences, as well as the mechanisms which facilitate the reasons.

\section{REFERENCES}

AHOLA, K., KIVIMÄKI, M., HONKONEN, T., VIRTANEN, M., KOSKINEN, S., VAHTERA, J., and LÖNNQVIST, J. (2008): Occupational burnout and medically certified sickness absence: A population-based study of Finnish employees. Journal of Psychosomatic Research, 64, 185-193.

ARONSSON, G., GUSTAFSSON, K., and DALLNER, M. (2000): Sick but yet at work. An empirical study of sickness presenteeism. Journal of Epidemiology and Community Health, 54, 502-509.

ARONSSON, G. and GUSTAFSSON, K. (2005): Sickness presenteeism: prevalence, attendance-pressure factors, and an outline of a model for research. Journal of Occupational and Environmental Medicine, 47, 958-966.

BÖCKERMAN, P. and ILMAKUNNAS, P. (2008): Interaction of working conditions, job satisfaction, and sickness absences: Evidence from a representative sample of employees. Social Science and Medicine, 67, 520528.

BÖCKERMAN, P. and LAUKKANEN, E. (2009): What makes you work while you are sick? Evidence from a survey of workers. The European Journal of Public Health, Forthcoming. 
BÖCKERMAN, P. and UUSITALO, R. (2006): Erosion of the Ghent system and union membership decline: Lessons from Finland. British Journal of Industrial Relations, 44, 283-303.

DEW K., KEEFE V., and SMALL K. (2005): 'Choosing' to work when sick: workplace presenteeism. Social Science and Medicine, 60, 2273-2282.

GOETZEL, R. Z., LONG, S. R., OZMINKOWSKI, R. J., WANG, S., and LYNCH, W. (2004): Health, absence, disability, and presenteeism cost estimates of certain physical and mental health conditions affecting U.S. employers. Journal of Occupational and Environmental Medicine, 46, 398-412.

HANSE, C. D. and ANDERSEN, J. H. (2008): Going ill to work - What personal circumstances, attitudes and work-related factors are associated with sickness presenteeism? Social Science and Medicine, 67, 956-964.

KIVIMÄKI, M., HEAD, J., FERRIE, J., HEMINGWAY, H., SHIPLEY, M. J., VAHTERA, J., and MARMOT, M.G. (2005): Working while ill as a risk factor for serious coronary events: The Whitehall II Study. American Journal of Public Health, 95, 98-102.

MIDDAUGH, D. J. (2006): Presenteeism: Sick and Tired at Work. MEDSURG Nursing, 15.

SCHULTZ, A. B. and EDINGTON, D. W. (2007): Employee Health and Presenteeism: A Systematic Review. Journal of Occupational Rehabilitation, 17, 547-579.

SIMPSON, R. (1998): Presenteeism, power and organizational change: long hours as a career barrier and the impact on the working lives of women managers. British Journal of Management, 15, 37-52.

WEBSTER, J. (2007): Diversity Management in the ICT Industry: Challenges and Issues for Social Dialogue. UNI Global Union, Report prepared for Union Network International. 
Table 1: The determinants of sickness presenteeism by gender.

\begin{tabular}{|c|c|c|c|c|}
\hline Gender: & Men & & Women & \\
\hline Policy variables & $\mathrm{DF} / \mathrm{dx}$ & Std. Err. & $\mathrm{DF} / \mathrm{dx}$ & Std. Err. \\
\hline Replacement by substitutes & -0.07 & 0.07 & $-0.18^{*}$ & 0.10 \\
\hline Replacement by colleagues & -0.02 & 0.06 & -0.16 & 0.10 \\
\hline Permanent full-time work & 0.01 & 0.07 & $0.19^{* * *}$ & 0.06 \\
\hline Working-hours match & -0.07 & 0.05 & $-0.11^{*}$ & 0.06 \\
\hline Shift or period work & 0.04 & 0.05 & 0.10 & 0.06 \\
\hline Regular overtime & $0.13^{*}$ & 0.08 & 0.11 & 0.11 \\
\hline$>48$ hours a week & $0.22^{*}$ & 0.14 & $0.27^{*}$ & 0.15 \\
\hline Three days' rule & $-0.09^{* *}$ & 0.05 & -0.07 & 0.06 \\
\hline Efficiency rule & 0.02 & 0.04 & $0.16^{\star *}$ & 0.06 \\
\hline Observed probability & 0.27 & & 0.35 & \\
\hline Predicted probability & 0.26 & & 0.33 & \\
\hline Pseudo $\mathrm{R}^{2}$ & 0.06 & & 0.10 & \\
\hline $\mathrm{N}$ & 424 & & 301 & \\
\hline
\end{tabular}

Notes: The models include the same unreported controls as in Appendix. Reported estimates are marginal effects from probit models, evaluated at variable means. * significant at $10 \%$; ${ }^{* *}$ significant at $5 \%$; ${ }^{* *}$ significant at $1 \%$. 
PRESENTEEISM IN FINLAND: DETERMINANTS BY GENDER AND THE SECTOR OF ECONOMY

Table 2: The determinants of sickness presenteeism by the sector of the economy.

\begin{tabular}{|c|c|c|c|c|c|c|}
\hline \multirow{2}{*}{$\begin{array}{l}\text { Sector of economy: } \\
\text { Policy variables }\end{array}$} & \multicolumn{2}{|c|}{$\begin{array}{l}\text { Processing } \\
\text { industries }\end{array}$} & \multicolumn{2}{|l|}{$\begin{array}{l}\text { Private } \\
\text { services }\end{array}$} & \multicolumn{2}{|c|}{ Public sector } \\
\hline & $\mathrm{DF} / \mathrm{dx}$ & Std. Err. & $\mathrm{DF} / \mathrm{dx}$ & Std. Err. & $\mathrm{DF} / \mathrm{dx}$ & Std. Err \\
\hline $\begin{array}{l}\text { Replacement by } \\
\text { substitutes }\end{array}$ & $-0.13^{*}$ & 0.07 & -0.16 & 0.12 & -0.05 & 0.14 \\
\hline $\begin{array}{l}\text { Replacement by } \\
\text { colleagues }\end{array}$ & -0.11 & 0.07 & -0.08 & 0.12 & 0.04 & 0.13 \\
\hline Permanent full-time work & 0.02 & 0.07 & $0.14^{*}$ & 0.07 & $0.17^{*}$ & 0.09 \\
\hline Working-hours match & $-0.12^{\star *}$ & 0.06 & 0.00 & 0.06 & -0.10 & 0.09 \\
\hline Shift or period work & 0.01 & 0.06 & $0.16^{\star \star *}$ & 0.06 & 0.02 & 0.09 \\
\hline Regular overtime & $0.24^{* * *}$ & 0.10 & -0.03 & 0.10 & 0.11 & 0.15 \\
\hline$>48$ hours a week & 0.15 & 0.15 & 0.07 & 0.17 & $0.57^{* *}$ & 0.13 \\
\hline Three days' rule & -0.04 & 0.05 & $-0.18^{* * *}$ & 0.06 & -0.04 & 0.10 \\
\hline Efficiency rule & 0.04 & 0.05 & $0.14^{* *}$ & 0.06 & 0.10 & 0.08 \\
\hline Observed probability & 0.27 & & 0.29 & & 0.38 & \\
\hline Predicted probability & 0.26 & & 0.25 & & 0.37 & \\
\hline Pseudo $\mathrm{R}^{2}$ & 0.07 & & 0.16 & & 0.13 & \\
\hline $\mathrm{N}$ & 334 & & 224 & & 167 & \\
\hline
\end{tabular}

Notes: The models include the same unreported controls as in Appendix. Reported estimates are marginal effects from probit models, evaluated at variable means. Robust standard errors reported. * significant at $10 \%$; ${ }^{* *}$ significant at $5 \%$; ${ }^{* * *}$ significant at $1 \%$. 
Appendix: Definitions of controls and policy varibables.

\begin{tabular}{|c|c|c|c|c|}
\hline Variables & Definition & All & Men & Women \\
\hline \multicolumn{5}{|l|}{ CONTROLS: } \\
\hline Primary level education & Reference & 23 & 22 & 24 \\
\hline Secondary education & Upper secondary $=1$, otherwise $=0$ & 65 & 69 & 59 \\
\hline Higher education & $\begin{array}{l}\text { More than secondary }=1 \text {, otherwise }= \\
0\end{array}$ & 13 & 9 & 17 \\
\hline$<35$ years of age & Reference & 23 & 25 & 20 \\
\hline $35-50$ years & Age $35-50=1$, otherwise $=0$ & 45 & 46 & 44 \\
\hline$>50$ years & Age $>50$ years $=1$, otherwise $=0$ & 32 & 29 & 36 \\
\hline Children & At least one child $=1$, otherwise $=0$ & 58 & 58 & 58 \\
\hline Less than 20 workers & Reference & 44 & 37 & 53 \\
\hline 20 - 50 workers & $20-50$ workers $=1$, otherwise $=0$ & 20 & 20 & 21 \\
\hline$>50$ workers & Over 50 workers $=1$, otherwise $=0$ & 36 & 44 & 26 \\
\hline \multicolumn{5}{|l|}{ POLICY VARIABLES: } \\
\hline No replacement & Reference & 11 & 14 & 8 \\
\hline $\begin{array}{l}\text { Replacement by } \\
\text { substitutes }\end{array}$ & By substitutes $=1$, otherwise $=0$ & 33 & 27 & 43 \\
\hline $\begin{array}{l}\text { Replacement by } \\
\text { colleagues }\end{array}$ & By colleagues $=1$, otherwise $=0$ & 55 & 60 & 49 \\
\hline Permanent full-time & $\begin{array}{l}\text { Permanent full-time work }=1 \text {, } \\
\text { otherwise }=0 \text { (fixed-term or part-time } \\
\text { work) }\end{array}$ & 88 & 92 & 82 \\
\hline Working hours match & $\begin{array}{l}\text { Desired and actual weekly working } \\
\text { hours match }=1 \text {, otherwise }=0\end{array}$ & 66 & 67 & 64 \\
\hline Shift or period work & Shift or period work $=1$, otherwise $=0$ & 41 & 40 & 43 \\
\hline Regular overtime & $\begin{array}{l}\text { Regular paid and unpaid overtime }= \\
1, \text { occasional or none }=0\end{array}$ & 11 & 12 & 9 \\
\hline$>48$ hours a week & $\begin{array}{l}\text { Weekly working hours more than } 48= \\
1, \text { otherwise }=0\end{array}$ & 4 & 4 & 4 \\
\hline Three days' rule & $\begin{array}{l}\text { Three days' paid sickness absence } \\
\text { possible without a sickness certificate } \\
\text { agreements }=1 \text {, otherwise }=0\end{array}$ & 45 & 38 & 55 \\
\hline Efficiency rule & $\begin{array}{l}\text { In tough situations efficiency rules out } \\
\text { everything else in firm, according to } \\
\text { the survey respondent }=1 \text {, otherwise } \\
=0\end{array}$ & 48 & 46 & 52 \\
\hline N & Number of observations & $\begin{array}{c}72 \\
5\end{array}$ & 424 & 301 \\
\hline
\end{tabular}

